\title{
Evaluation of seismic loads on elevated storage tanks
}

\author{
G. Perillo ${ }^{1} \&$ M. Rizzone ${ }^{2}$ \\ ${ }^{I}$ Department of Technology, Naples Parthenope University, Italy \\ ${ }^{2}$ S.A.P.NA. SpA, Naples, Italy
}

\begin{abstract}
Suitable response of hydraulic structures to seismic actions represents an important requirement in order to organise aid in the areas damaged by seismic events; therefore accurate assessment of hydrodynamic loads acting on the structure represents the first step in a correct anti-seismic structural design.

With particular reference to water storage tanks, the problem of hydrodynamic actions exerted by an earthquake on the walls of a tank has been investigated, whether fully or partially buried below ground and considered to be non-deformable ('rigid' scheme), and the tank's tendency to deform has been analysed, taking into account the liquid-shell interaction ('elastic' scheme) and highlighting its sometimes significant influence on the entity of hydrodynamic actions.

The aim of this research project is to analyse elevated storage tanks in seismic areas, comprising a tank mounted on a single vertical column. Applying the same considerations made for 'ground-based' tanks to such a scheme is immediately possible because the liquid mass fully enters the energy balance of the structural system and its quantity does not vary over time and formal variations in the hydraulic profile over time do not entail substantial modifications in the system's overall response.

Analysis of the dynamic response of elevated tanks, performed by means of the mathematical model described and limited to concrete structural systems with a circular tank, has shown that the entity of hydrodynamic motions can be significant and, furthermore, noticeably greater than those for equally sized tanks on the ground.

Keywords: hydrodynamic effects, seismic motions, elevated storage tanks.
\end{abstract}




\section{Introduction}

Correct antiseismic planning of hydraulic structures (such as dams, storage tanks, water supply networks etc.) is particularly important in high-risk countries like Italy because, in the event of an earthquake, their functionality will not be compromised and potentially major damage that could derive from faulty planning may be avoided. Indeed, as water availability plays an important role in initial rescue operations and in the recovery of the afflicted areas over time, it is necessary to perform a thorough analysis of the "seismic reliability" of the hydraulic works and structures regarding:

- the characterization of the envisaged seismic loads and the resulting assessment of the hydrodynamic actions induced by the earthquake (in addition to the hydrostatic pressure and the inertial actions related to structural masses) [1];

- an estimate of the structural response and an examination of the construction devices (with particular attention to dissipators) to use in order to reduce damage caused by a seismic event.

It must be pointed out that in Italy there is no specific law regulating water storage tanks while in other countries, like the U.S.A., such procedures have long been in use: for instance, the HCLPF (High Confidence of a Low Probability of Failure), developed for hydraulic containers in nuclear plants [2]. In relation to the aforementioned problems, the Department of Hydraulic and Environmental Engineering at Naples University has been studying these issues for some time now [3-7].

With particular reference to water storage tanks, we have investigated the problem of hydrodynamic actions exerted by an earthquake on the walls of a tank, whether fully or partially buried below ground and considered to be nondeformable ('rigid' scheme) [8], and we have analysed the tank's tendency to deform, taking into account the liquid-shell interaction ('elastic' scheme) and highlighting its sometimes significant influence on the entity of hydrodynamic actions $[9,10]$.

The aim of this research project is to analyse elevated storage tanks in seismic areas, comprising a tank mounted on a single vertical column. Applying the same considerations made for 'ground-based' tanks to such a scheme is immediately possible because of the following considerations:

- the liquid mass fully enters the energy balance of the structural system and its quantity does not vary over time;

- formal variations in the hydraulic profile over time do not entail substantial modifications in the system's overall response. In other words, excluding exceptional conditions, these are such as not to increase stress to any significant degree.

This explicitly means that the hydrodynamic motion can be assumed to be equivalent to that for ground-based tanks by substituting soil acceleration for that of the container-liquid combined. 


\section{The motion of the liquid inside the tank}

The hydrodynamic motions generated by an external force on a rigid tank, whether on the ground or elevated, can be evaluated by means of different mathematical models (for example, Jacobsen, Housner, Bratu, Veletsos [8]). Of these, we have used Bratu's model [11] because of its greater generality (which will be discussed below) developed for a rectangular hydraulic tank subjected to horizontal seismic acceleration acting in any direction on the tank wall.

The author refers to the usual simplified hypotheses, also used elsewhere, which are generally reliable in technical terms, as confirmed by experimental research [12]:

- $\quad$ Rigid tank and two-dimensional motion;

- $\quad$ Perfect, homogeneous, isotropic and non-viscous fluid (dissipation phenomena due to friction are thus ignored);

- Incompressible fluid and negligible surface tension;

- $\quad$ Non-rotational motion of the elementary particles;

- Small wavelength (to linearize motion equations) and harmonic fundamental motion.

On the basis of these hypotheses, with the solution of the Laplace equation and with adequate boundary conditions, namely:

- $\quad$ Absence of discontinuity between bottom of the tank and liquid;

- $\quad$ Fluid particles adhering to the tank walls;

- Absence of horizontal components in the gravitational forces.

Bratu identifies the expression of the velocity potential into which the seismic acceleration is introduced. The author then evaluates the velocity expressions and the trajectory of the fluid particles (and thus the fluid's free surface profile), the distribution of the hydrodynamic pressures exerted on the walls - deduced from the linearized motion equation - which is parabolic, and the resulting force. The author, however, neglects the gravitational component gz in applying the linearized equation.

$$
-\frac{\partial \phi}{\partial t}+\frac{p}{\rho}+g \cdot z=0
$$

As already noted in calculations, this results in an anomaly in the pressure distribution (and consequently in the values of the force): it assumes a non-zero value in proximity of the free surface, where it should in fact be zero (as in all other examined models). It even attains a negative value when the earthquake period is smaller than that of the fluid oscillation (as happens in most cases), and remains such down to a certain depth, which varies according to the tank's geometry and the earthquake's period.

Applying equation (1) in its complete form makes it possible to eliminate this anomaly, obtaining the following relations for the evaluation, in proximity of the 
wall, of the impulse pressure distribution, pw, - which, as already pointed out, is parabolic - of the resultant force, $\mathrm{Sw}$, and of the maximum height, $\eta$ (Fig. 1):

$$
\begin{gathered}
\mathrm{p}_{\mathrm{w}}(\mathrm{z})=\frac{4}{\pi^{2}} \cdot \gamma \cdot \mathrm{C} \cdot \delta_{\mathrm{r}} \cdot \frac{\mathrm{T}_{\mathrm{w}}{ }^{2}}{\mathrm{~T}_{\mathrm{s}}{ }^{2}-\mathrm{T}_{\mathrm{w}}{ }^{2}}\left[\frac{\cosh \cdot \mathrm{k}_{\mathrm{r}}(\mathrm{z}+\mathrm{H})}{\cosh \cdot \mathrm{k}_{\mathrm{r}} \mathrm{H}}-1\right] \\
\mathrm{S}_{\mathrm{w}}=\frac{4}{\pi^{2}} \cdot \gamma \cdot \mathrm{C} \cdot \mathrm{H} \cdot \delta_{\mathrm{r}} \cdot \frac{\mathrm{T}_{\mathrm{w}}{ }^{2}}{\mathrm{~T}_{\mathrm{s}}{ }^{2}-\mathrm{T}_{\mathrm{w}}{ }^{2}} \cdot\left[\frac{\tanh \left(\mathrm{k}_{\mathrm{r}} \mathrm{H}\right)}{\mathrm{k}_{\mathrm{r}} \mathrm{H}}-1\right] \\
\eta=\frac{4}{\pi^{2}} \cdot \mathrm{C} \cdot \delta_{\mathrm{r}} \cdot\left[1+\frac{\mathrm{T}_{\mathrm{w}}{ }^{2}}{\mathrm{~T}_{\mathrm{s}}{ }^{2}-\mathrm{T}_{\mathrm{w}}{ }^{2}}\right]
\end{gathered}
$$
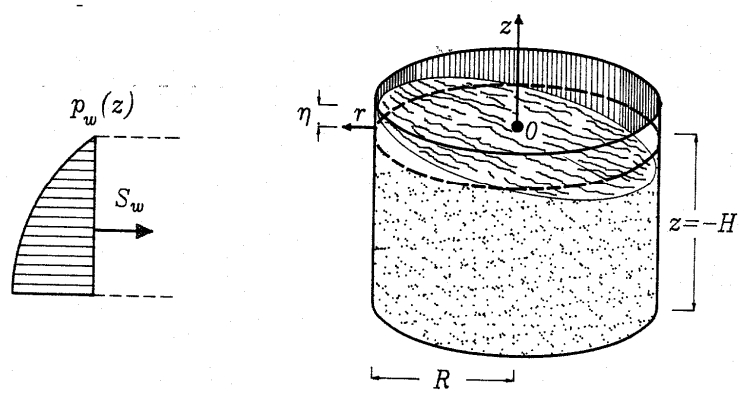

Figure 1: Cylindrical tank: schem of reference.

In the previous relations we have used the following notation:

- $\quad \gamma$ : fluid specific weight;

- $\quad$ C: seismic intensity coefficient;

- $\quad a, b$ : tank size $(a \geq b)$;

- $\alpha$ : angle between the earthquake direction and the longest side of the tank;

- $\quad \mathrm{H}$ : head;

- $\quad$ z: depth (from the steady fluid level);

- $\delta_{\mathrm{r}}=\mathrm{a} \cdot \cos \alpha+\mathrm{b} \cdot \sin \alpha$;

- $\mathrm{k}_{\mathrm{r}}=\pi \sqrt{1 / \mathrm{a}^{2}+1 / \mathrm{b}^{2}}$

- $T_{w}=\frac{2 \pi}{\sqrt{g k_{r} \tanh \left(k_{r} H\right)}}:$ fundamental period of the oscillation of the liquid mass;

- $\frac{\mathrm{T}_{\mathrm{w}}{ }^{2}}{\mathrm{~T}_{\mathrm{S}}{ }^{2}-\mathrm{T}_{\mathrm{w}}{ }^{2}}$ : cyclical amplification factor, where $\mathrm{Ts}$ is the fundamental period of the system. 
Unlike other simpler treatments (for example Housner and Jacobsen [8]), the presence of the amplification factor in relations (2), (3) and (4) makes it possible to take into account the interaction between the period of the earthquake and that of the fluid mass, thus highlighting the different hydrodynamic response as the geometric features and the fluid level vary. We can observe, in this connection, that Bratu believes that only for large containers (for which the period Tw tends towards very high values and the height tends towards low values) can we use a 1 amplification factor value: this would eliminate the aforementioned anomaly.

Bratu's treatment has also been extended to circular cross-section tanks (Fig. 1), obviously taking into account the gravitational term in the motion equation (this will be more detailed in a note currently nearing completion by the above-mentioned research group): of course the polar symmetry of the structure renders the direction of the seismic acceleration non-influential, thus simplifying the expression of the velocity potential. Referring to the fundamental fluid oscillation (which also in this case causes maximum wave heights and more significant hydrodynamic stresses) the expressions for $\mathrm{pw}$, Sw and $\eta$ have been deduced, which turn out to be formally analogous to those for four-sided tanks, substituting the expressions for $\mathrm{\delta r}$ and $\mathrm{kr}$ with the following:

$$
\begin{gathered}
\delta_{c}=\pi \cdot R \\
\mathrm{k}_{\mathrm{c}}=\pi / 2 \mathrm{R}
\end{gathered}
$$

where $\mathrm{R}$ is the tank radius.

\section{Elevated tanks}

It must first be pointed out that, for the purpose of evaluation, the vertical column-tank system can be schematized in:

- $\quad$ an elastic scheme, considering the deformability of both the column and the tank;

- $\quad$ a mixed scheme, considering the column to be deformable and the tank rigid.

Obviously this choice must be made by referring to the structural characteristics of the real column-tank system considered: shapes, materials used and dimensions. In this first phase of the research, we consider an elevated circular concrete tank with a truncated cone fixed to the column (such as to ensure conditions of perfect and reciprocal fit) (Fig. 2). Given the characteristics of the structural system examined, we consider that the deformability of the tank (mixed scheme) may be neglected without causing any significant error.

However, it should be noted that while a tank standing on the ground is directly stressed by the seismic acceleration, for an elevated tank on a flexible column the masses in play (column + tank + liquid) absorb the earthquake's energy which is spread through the system's foundations.

As a result, we can consider the hydrodynamic response of the fluid equal to that of a ground-based tank, as long as the acceleration of the base is substituted with that of the elevated tank. The theoretical model in the dynamic field to 
which we have referred is that of an elastic shelf with distributed mass and other mass on top (fig. 2).
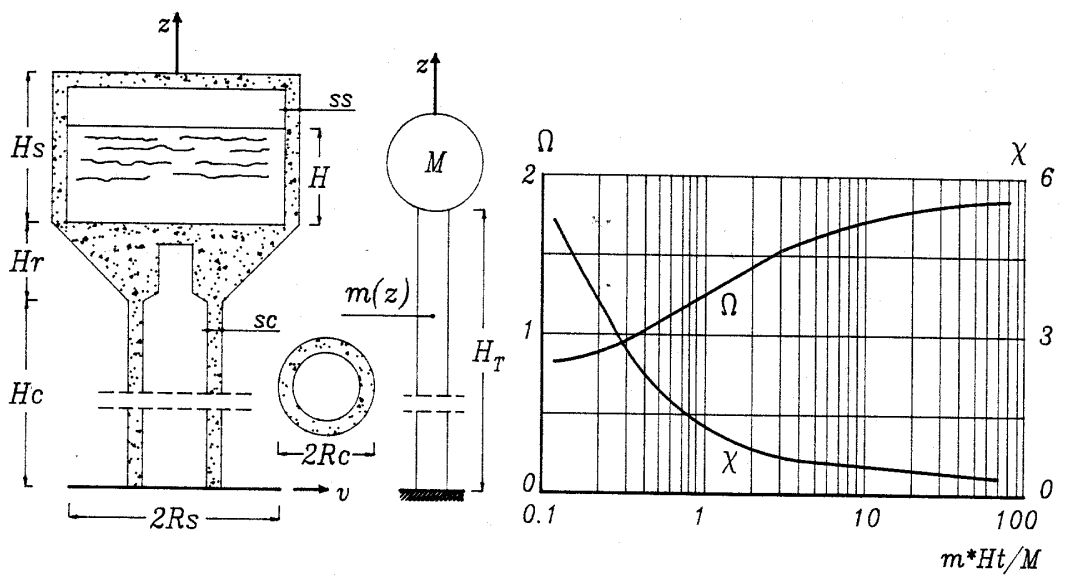

Figure 2: $\quad$ Elevated storage tank: system considered.

The fluid, or rather the portion of it that takes part in the motion, has a fundamental period Tw, as if it were ground-based: indeed, the expression Tw depends exclusively, as seen before, on the geometry of the container and the amount of fluid it contains. The classic differential equation for the problem of the free oscillations of a system composed of a constant column and that of the frequencies can be expressed as [13]:

$$
\begin{gathered}
\mathrm{EI} \cdot \frac{\mathrm{d}^{4} \mathrm{v}}{\mathrm{dz}}-\mathrm{m} \cdot \omega_{\mathrm{s}}{ }^{2} \cdot \mathrm{v}(\mathrm{z})=0 \\
\Omega \cdot \frac{(\sin \Omega \cdot \cosh \Omega-\cos \Omega \cdot \sinh \Omega)}{1+\cos \Omega \cdot \cosh \Omega}=\frac{\mathrm{m} \cdot \mathrm{H}_{\mathrm{T}}}{\mathrm{M}} \cong \frac{\mathrm{m} \cdot\left(\mathrm{H}_{\mathrm{c}}+\mathrm{H}_{\mathrm{r}}+0.5 \cdot \mathrm{H}_{\mathrm{s}}\right)}{\mathrm{M}}(6)
\end{gathered}
$$

where:

- $\Omega=\mathrm{H}_{\mathrm{T}} \cdot \sqrt[4]{4 \pi^{2} \cdot \mathrm{m} / \mathrm{T}_{\mathrm{s}}^{2} \cdot \mathrm{EI}}$

- $\omega_{\mathrm{s}}=2 \pi / \mathrm{T}_{\mathrm{s}}$ : frequency of the structural system;

- $\quad \mathrm{M}$ : mass of the tank (joint included) and the liquid;

- $\quad \mathrm{m}$ : mass per column unit length;

- $\mathrm{H}_{\mathrm{T}} \cong \mathrm{H}_{\mathrm{c}}+\mathrm{H}_{\mathrm{r}}+0.5 \mathrm{H}_{\mathrm{s}}$ (with a good degree of approximation) (fig. 3);

- $\quad \mathrm{E}$ : elastic module of the material;

- I : transversal moment of inertia of the column.

For the fundamental motion, the values of $\Omega$ are shown in the diagram in Fig. 3 as a function of $\mathrm{mHT} / \mathrm{M}$, as are those of the relative participation factor $\chi$. 
The deformation expression at the tank height, $\mathrm{v}(\mathrm{HT})$, and the corresponding inertial force, $\mathrm{F}(\mathrm{HT})$, are:

$$
\begin{gathered}
\mathrm{v}\left(\mathrm{H}_{\mathrm{T}}\right)=\sin \Omega-\sinh \Omega-\frac{\sin \Omega+\sinh \Omega}{\cos \Omega+\cosh \Omega}(\cos \Omega-\cosh \Omega) \\
\mathrm{F}\left(\mathrm{H}_{\mathrm{T}}\right)=\mathrm{M} \cdot \chi \cdot \omega_{\mathrm{s}}^{2} \cdot \mathrm{v}\left(\mathrm{H}_{\mathrm{T}}\right) \cdot \mathrm{S}_{\mathrm{d}}=\mathrm{M} \cdot \chi \cdot \mathrm{v}\left(\mathrm{H}_{\mathrm{T}}\right) \cdot \mathrm{S}_{\mathrm{a}}
\end{gathered}
$$

where $\mathrm{Sd}$ and $\mathrm{Sa}(\mathrm{Sa}=\mathrm{C} \cdot \mathrm{g})$ are respectively the spectral values in terms of displacement and acceleration.

Consequently, the seismic intensity coefficient $\mathrm{Cp}$ to insert into (2) (3) and (4) for elevated tanks, excluding any response coefficient, is:

$$
\mathrm{C}_{\mathrm{p}}=\mathrm{C} \cdot \mathrm{v}\left(\mathrm{H}_{\mathrm{T}}\right) \cdot \chi
$$

which can be defined as the structural amplification factor.

In the first phase of study regarding columns with a constant cross-section, a program was developed to enable the sizing of the tank-column structural system, the dynamic calculation and the evaluation of the consequential hydrodynamic effects on the elevated tank (pressure distribution, resultant force, and height).

In an attempt to generalize the problem with variable cross-section columns, we later found ourselves faced with extremely complex mathematical settings [14]. It was thus decided to conduct a sensitivity analysis of numerous cases in order to investigate whether a suitable discretization $(10 \%)$ of the column would provide the finite elements of comparable solutions with the exact mathematical formulation [15]. The result confirmed deviations not greater than a few units per thousand between the continuous and the discrete setting [16].

\section{A practical example}

As a first area of investigation we focused our attention on elevated circular cross-section concrete tanks, by performing some calculations in order to analyse dynamic response as the column features and the water filling level vary.

These preliminary calculations show that in an elevated tank located in a class one seismic area $(\mathrm{C}=0.10)$ a higher column causes greater hydrodynamic effects, although only to a slight degree. Instead, with a tank standing on the ground the response is quite different, subjected to a seismic acceleration equal to $0.10 \mathrm{~g}$ with period Ts equal to $1 \mathrm{~s}$. So, for elevated storage tanks in seismic areas the hydrodynamic effects can clearly be significantly greater than those for tanks of the same dimensions on the ground.

Further investigations need to be made on the reciprocal influence between the pulses of the earthquake and those of the structural system. Characteristic peak values of the dynamic response and, consequently, the hydrodynamic parameters could derive from the use of the accelerometric spectrum of a typical 'local' earthquake in correspondence of the fundamental period of the structurefluid system. For instance, for the elevated tank considered, the period in maximum filling conditions is equal to $0.41 \mathrm{~s}$ for $\mathrm{Hc}=15 \mathrm{~m}$ and $0.76 \mathrm{~s}$ for $25 \mathrm{~m}$ : 
adopting the spectrum of Italian standards, the spectral acceleration Sa is equal to that on the ground $(0.10 \mathrm{~g})$. On the basis of the Tolmezzo (Friuli) recording spectrum, we can deduce a value of Sa equal to about $2.65 \mathrm{~m} / \mathrm{s} 2$ in the first case and $1.8 \mathrm{~m} / \mathrm{s} 2$ in the second, with a consequential increase in values to 0.43 and 0.31 .

\section{First considerations}

Analysis of the dynamic response of elevated tanks, performed by means of the mathematical model described and limited to concrete structural systems with a circular tank, has shown that the entity of hydrodynamic motions can be significant and, furthermore, noticeably greater than those for equally sized tanks on the ground.

Research is currently in progress, both on different structural shapes and materials (steel for example) and on the possibility of using dissipation systems to minimize the effects of an earthquake. Furthermore, a simpler and mechanically equivalent model (according to the scheme proposed by Housner [8]) is currently under development, in order to provide technical staff with a better instrument for quick and reliable evaluations.

\section{References}

[1] Chandler A.M., Evaluation of site-dependent spectra for earthquakeresistant design of structures in Europe and North America, The Institution of Civil Engineers, Proceedings, Part I, Vol. 90, 1991.

[2] Hashimoto P.S., Basak A.K., Seismic Capacity and Failure Modes of FlatBottom Vertical Tanks, Journal of Energy Engineering, Vol. 119, No. 2, August, ASCE, 1993.

[3] De Martino, G., Giugni, M., Effetti idrodinamici sulle dighe di sbarramento durante terremoti, Giornale del Genio Civile, Fascicolo $4^{\circ}-5^{\circ}-6^{\circ}$, AprileMaggio-Giugno, 1983.

[4] De Martino, G., Giugni, M., De Marinis, G., Hydrodynamic Pressures on Dams during Earthquakes - Approximate Formulation, Earthquake Resistant Engineering Structures 96, Thessaloniki, Greece, 1996.

[5] De Martino, G., Giugni, M., Azioni idrodinamiche su una diga in zona sismica. Proposta integrativa alla normativa vigente, Giornale del Genio Civile, Fascicolo $10^{\circ}-11^{\circ}-12^{\circ}$, Ottobre-Novembre-Dicembre, 1992.

[6] De Martino, G., Giugni, M., Perillo G., Condotte interrate in zona sismica. Effetti dinamici, Scritti in onore di Girolamo Ippolito, Vol. II, CUEN, 1991.

[7] De Martino, G., De Marinis, G., Giugni, M., Risposta dinamica di tubazioni di drenaggio in zona sismica, Idrotecnica, n. 1, 1994.

[8] De Martino, G., Giugni, M., Azioni delle onde sismiche sui contenitori idraulici interrati, Giornale del Genio Civile, Fascicolo $10^{\circ}-11^{\circ}-12^{\circ}$, Ottobre-Novembre-Dicembre, 1989.

[9] Giugni, M., De Marinis, G., Perillo, G., L'affidabilità delle strutture idrauliche in zona sismica, Seminario sulla "Affidabilità dei sistemi di 
adduzione e di distribuzione idrica (nella progettazione, nell'esecuzione e nella gestione)", Fisciano, Univ. degli Studi di Salerno, 1995.

[10] Giugni, M., De Marinis, G., Perillo, G., Sovrappressioni idrodinamiche su contenitori deformabili in zona sismica, $7^{\circ}$ Convegno nazionale ANIDIS "L’ingegneria sismica in Italia", Siena, Vol. II, 1995.

[11] Bratu, C., Sul comportamento in regime sismico dei liquidi contenuti in serbatoi rettangolari, IX Convegno di Idraulica e Costruzioni Idrauliche, Trieste, 1965.

[12] Cenedese, A., Marchetti, M., Siclari, G., Analisi sperimentale del moto di un liquido in un serbatoio parallelepipedo oscillante, 17. Convegno di Idraulica e Costruzioni Idrauliche, Palermo, 1980.

[13] Como, M., Lanni, G., Elementi di costruzioni antisismiche, A. Cremonese, 1979.

[14] Sarà, G., Ingegneria antisismica, Liguori, 1985.

[15] Ramasco, R., Dinamica delle Strutture. CUEN, 1993.

[16] Santorelli, S., Dinamica delle Strutture ed Ingegneria Sismica. CUEN, 1991. 